of the need or tendency to use several drugs concurrently. Patient treatment profiles could well be kept by pharmacists, and this would surely be valuable to the doctor and essential to the deputising doctor who often prescribes "cold" without knowledge of either patient or drug-taking record. Pharmacists could well carry out more safely than the receptionist repeat prescribing or referral back to the doctor.

Many years ago I enjoyed an apprenticeship where my master and fourteen doctors had absolute mutual respect and trust and would have died rather than let each other down. We need discussion as to how we help each other and co-exist, but you have made a commendable start and I congratulate you. Let us go forward to greater respect for each other and stop griping.

J GEOFFREY ROBERTS Mersey Regional Health Muthority, Liverpool

\section{Health Service Commissioner and the Rhyl case}

SIR,-In his understandable wish merely to summarise the disturbing features of the incident at Rhyl, Dr David Williams (14 October, p 1090) gives insufficient detail about the factor of the wishes of the patient in the case.

As I understand it, the patient did not wish to be admitted to hospital. If that were so, she could, I think, be detained if she required to be removed to a place of safety; but indeed she wished to return to one. Otherwise she could only be detained under the Mental Health Act 1959.

But the Government is in process of loosening the compulsory clauses of that Act, and the Select Committee of the House must be well aware of it. So while some eminent ladies and gentlemen may individually or as a group consider that it may have been "inhuman" to send the patient back to the home, it would have been illegal for the doctor to have detained her, and might become even more illegal in the future!

For the Ombudsman and Parliament, then, the score is still Rhyl-nil.

Alresford, Hants

JOHN HAPPEL

\section{Medical manpower: the next twenty years}

SIR,-You have published an extract of the DHSS paper on medical manpower (7 October, p 1032); it makes depressing and discouraging reading. It is not a paper really, but a long list of questions for the profession to answer and offers work for several working parties for the next decade, by which time we shall have the answer, correct or not, in the number of medical students going through universities. One of the questions is particularly banal, the one about increasing the productivity of doctors by the better use of technology. This is meaningless; doctors don't produce anything-we are physicians, which means that we use our treatments and our medicines against diseases which affect people, and we use our powers of persuasion, based on our knowledge of pathology, to try to educate people to follow a life style which is most conducive to the maintenance of health: at least that is what I think we should be doing. Much of what I do could be done by a district nurse, a health visitor, a consultant, a priest, a social worker; but if it were that would no increase my productivity: it would reduce my work load-then I could take on more patients and continue to delegate, thus still not increasing my productivity but elevating my income. If we attempt to define the jobs of the different workers in health care, then we shal see the spectre of demarcation disputes and income differentials, two of the contributors to the present industrial unrest: better not to have that in medicine. Besides, I don't believe people should have to be ill if they wish to consult a doctor; we are counsellors as well as diagnosticians and therapists, and advice can be a powerful form of treatment.

Health is the most precious possession an individual can ever have, though few appreciate that until they have lost it. Doctors have enjoyed a unique privileged position in societies, though I doubt if we deserve it all. More doctors, however, will not mean better health. I am sure we have plenty of doctors in Britain: a ratio of approximately one for each thousand of population is a rich endowment of medical personpower. Why can we not accept this, and spend our energies more fruitfully studying what we do, instead of wasting time guessing how many of us should be doing it? I fail to see how any other organisation but the medical profession can be in a position to know how many doctors are needed. We should be giving the lead and telling the DHSS, not waiting for their long lists of questions and then entering interminable discussions and getting very little at the end of it. Can the BMA not be firm for once?

R M MILNE

Uphall,

\section{Medical care in inner cities}

SIR,-I have seen the further correspondence on this subject, including the letter from Professor D C Morrell (23 September, p 890) of St Thomas's Hospital Medical School (whose appointment includes patient care in its terms, and thus ensures he can practise what he teaches).

General practice was refinanced 13 years ago, which led to substantial improvements for a modest price. The Government should now lavish funds on academic departments in the subject. Such funding would permit experiments in the teaching of integrated primary care, would bring service and research to where it is needed, and provide a focus for practitioners, as our teaching hospitals do for consultants. London shows many of the problems of providing primary medical care, and yet at the opposite sides of "The Great Wen" neither the London Hospital Medical School nor the Royal Postgraduate Medical School have such academic departments-no wonder locally trained graduates choose Winchester, not Whitechapel.

Professor Morrell regards the question of recruitment to practice as crucial, and doctors qualified abroad have gained experience as assistants which gives them a great advantage with selection committees. However, Professor Margot Jefferys found in Camden that many single-handed, isolated, elderly doctors were immigrants who had escaped religious per- secution and settled for what little opportunity was available. ${ }^{1}$ Our young overseas doctors also settle in the inner cities, as there is little local competition for these posts, and this perpetuates the problem of isolation. This also occurs in the inner cities of the United States.

The GMSC and Government should negotiate an age of retirement for practitioners working in the health service, to be brought into line with other doctors. This would deal honourably with the isolated elderly doctors, and make way for the more active service of local need.

London NW10

RONALD LAW

Sidel, V W, Jefferys, M, and Mansfield, P J, fournal of the Royal College of General Practitioners, 1972,

General ophthalmic services-a practical alternative

SIR,-The general ophthalmic services cost $1.2{ }^{\circ}$ of the total NHS budget: an estimated f96m in 1978. ${ }^{1}$ One-third of this is spent on sight tests and around six million pairs of NHS spectacles are issued yearly. The Prices Commission was recently reported to be investigating the cost of spectacles, so it is perhaps time for an objective re-examination of the long-standing agreement between the NHS and private opticians over the sale of spectacles to the public.

It was once considered deplorable that many people bought their reading glasses in multiple stores, but that was before the days of free access to general and specialist medical care. In many countries that have universal health care there is no such prohibition of the free sale of reading glasses, the demand for which is overwhelmingly from persons aged over 40 , without eye disease or astigmatism.

When in Canada I preferred not to have the free refraction to which I was entitled from an ophthalmologist under Provincial Health Insurance, but I chose instead an excellent pair of reading glasses for $\$ 5.50$ from a multiple store. I still prefer them to the rather utilitarian NHS pair that cost me twice as much over here, with an additional charge to the NHS. I have in front of me a mail order catalogue from the USA advertising reading glasses in attractive two-tone frames for \$3.95. Such glasses are often accompanied by a leaflet describing the symptoms of serious eye disease and this could be made mandatory.

The free sale of reading glasses would undoubtedly reduce the financial burden on the public and on the NHS and would allow the ophthalmic services to concentrate on more complex cases.

Social Services Department,

M J BaLl Hertfordshire Area

Office of Health Economics, The Cost of the NHS, Briefing No 7. London, OHE, 1978.

\section{Staffing structures and racial discrimination}

SIR,-It was inevitable that the Race Relations Board would interest itself in the fortunes of coloured doctors within the hospital service; after all, there is apparent evidence of widespread discrimination. Coloured juniors tend to be employed in the periphery rather than in teaching centres. Recently published figures 
support the view that their chances of promotion to senior registrar are poor, except in specialties which are unattractive to their white colleagues; and that even in these specialties the prospects of promotion to consultant are worse than those of the white senior registrar. ${ }^{1}$ Even the royal colleges could be subjected to scrutiny, as the coloured doctor performs relatively badly in their examinations.

All of these facts can be explained on grounds other than those of racial discrimination, and it is important that the Race Relation Board be made aware of the main cause of the problem, lest it produce a report lacking the insight one might expect. The nub of the matter is that the hierarchical pyramid leading from house officer to consultant is too wide at registrar and senior registrar levels. As a result, competition is excessive at registrar level and in most specialties remains too great even at senior registrar level. In such a situation the weak go to the wall-be they female doctors, doctors who interview badly, doctors with speech impediments, effeminate doctors, etc, as well as those with coloured skins.

As the criteria for deciding appointees are multiple, selection committees may not be guilty of racial discrimination, even when seeming to be so; and if they are guilty, this would be a difficult thing to prove.

The Race Relations Board, therefore, would be wise to lend its weight to those who seek improvement in the staffing structures in our hospitals, as well as investigating the general case and those individual examples of racial discrimination which come to its attention.

TOM MCFARLANE

Manchester

Health Trends, 1978, 10, 61

\section{Militancy in ambulance service}

SIR,-The intrusion of union militancy into the ambulance services must be of concern to all those who believe in a caring society. Until recently these services and the men who serve in them have had the respect and admiration of all.

It now appears that the National Union of Public Employees has issued, as official policy, instructions to their members that they should discriminate against any member of the public who is conveyed to a private nursing home. A few militant ambulancemen have interpreted this instruction as a clarion call to carry the banner of class warfare. The irony of the situation is that the poor souls who suffer are, in the main, frail and elderly NHS patients for whom room cannot be found in NHS hospitals. There have been recent instances, of which $\mathrm{Mr}$ David Ennals has been made aware, in which such people have been treated with callous disregard for their physical and mental welfare. From correspondence with his department, it is evident that he is aware of the situation but is prepared to accept it. Apparently, an edict of NUPE is sacrosanct, inviolable, and unchallengeable.

I suggest that this is an instance of the blatant misuse of union power by those who care nothing for their fellows, and to whom militancy is an end in itself. I hope that the executive of NUPE will honestly be able to refute this suggestion. It would be interesting to hear from doctors in other areas whose patients have been similarly distressed and so to assess the extent of this disturbing development in an admirable public service.

\section{A S OGDEN Communicating with patients}

Bournemouth

\section{Clinical medical officers}

SIR,-May I bring to your attention some important issues in your report of the Central Committee for Community Medicine meeting (7 October, $p$ 1038) ? In referring to clinica medical officers, Dr Preston states that these doctors "spent up to $80 \%$ of their time on child health.... [They] had many other commitments besides. ..." This is a distortion of facts to make a "generic" service look reasonable.

Our survey, with 700 replies, shows that $54 \%$ of doctors do nothing but child health $26 \%$ do more than half-time child health (half of these do nine sessions of child health and one of family planning). Only $6 \%$ do no child health, and almost all of these are "purists" and do all geriatrics, all family planning, etc. The only "generic" combination appears to be child health and family planning.

Your report is interesting when compared with that of the community medicine conference (29 July, p 376). At that meeting some of us tried to insert the phrase "acceptable to the doctors at present working in the clinical services of the community" (which seemed reasonable enough request) in a motion on career structure of clinical medical officers. Dr J S Horner "advised rejection." There wa the strong implication that an offer from the DHSS was imminent.

The report of 7 October makes it clear that we were misled, and no such offer is, fortunately, about to be made. Once more th clinical medical officers are being treated as second-class doctors, pawns in a powerful political game. I quote from your issue of 29 July: Dr Horner, who is our self-chosen spokesman, said that "if we do not set our minds to the problem of how we organise and maintain an effective group of community health doctors concerned with a wide variety of clinical interests... we shall find we have handed over our future for someone else to determine." Whose future ? Not ours.

Finally, in case the last sentence in you report of 7 October encourages people to believe that democracy has returned and we are being represented in discussions on our future, let me assure them that, much as we value Dr Anne Jepson's support and help, sh is a community physician and not, as stated, member of the Association of Clinical Medica Officers. If your readers are becoming wearied with the mention of clinical medical officers, may I suggest that they remember that the country spent as much money on our medical education as on theirs, and that therefore there should not be a second-class group of doctors who are "managed" by others, especially alien administrators? (Doctors in the Forces presumably chose a subordinate role.

So we ask the medical profession to help us get a satisfactory career, with an independent status, within our chosen specialties. Hospital medicine surely needs to look outwards into the community as we approach the 1980 s.

SHELAGH M TYRRELL. Chairman,
Mr A G Butters (Cawthorne, South Yorks) writes: Few papers stress the importance of adequate communication with the patient; it was good to read the late Miss Sydney Foott's stimulating Personal View (30 September, p 950). During my active surgical life I urged the staff never to forget to put themselves in their patients' position. Explanation and reassurance to a patient, the majority of whom are apprehensive, should be considered an essential part of any form of therapy. There is nothing new in the approach, but in the present era of change in medical outlook it is well to have a rethink on this vital subject. Perhaps our medical schools could place more emphasis on the importance of learning to become a practising personal doctor, for understanding and compassion, as in all skills, require thoughtful study.

\section{Co-operation between GPs and pharmacists}

Dr S A Hall (Exeter) writes: When GPs are constantly complaining that they are overwhelmed by trivia which are equally well treated by a proprietary remedy and pharmacists, more recently, that they have under-used capacity for the management of more serious illness, then the scene is set for greater co-operation between these two providers of primary care. But ... a GP may be dealing with 10 chemists and a chemist with 10 GPs. For useful co-operation and mutual professional satisfaction GP and chemist must operate from the same building.... The regulations should be amended to allow an interested pharmacist to ply his trade from the premises of a co-operating group practice. There is already a precedent for the mixture of NHS and private enterprise with ophthalmic medical practitioners prescribing in shops which sell magnifying glasses in addition to dispensing lenses. ...

\section{Toilet paper and spread of infection}

Dr R E W FisheR (London N5) writes: Dr I Taylor (7 October, p 1024) sees a connection between the changeover from hard to soft toilet paper and the decline in notifications of dysentery in England and Wales. But in 1950 or thereabouts the width of a standard sheet of toilet paper was $130 \mathrm{~mm}$; the width of a sheet of toilet paper bought a few weeks ago is 114 $\mathrm{mm}$ and of a sheet bought this week $105 \mathrm{~mm}$. I offer the hypothesis that these tiny sheets are apt to result in obvious soiling of the fingers, which compels immediate hand washing. Of course, both hypotheses are improbable. What is quite certain is that these tiny sheets of toilet paper are disgusting and insanitary.

\section{Farm ecology?}

Professor J T AITKEN (University College, London) writes: Surely one of the choicest homophones is reported in the press to have headed an Oxford University pass list. Candidates in pharmacology were listed under farm ecology. 